\title{
Risk Factors Associated with the Fear of Falling in Community-Living Elderly People in Korea: Role of Psychological Factors
}

\author{
Jong-II Park ${ }^{1,2}$, Jong-Chul Yang, ${ }^{1,2}$, and Sangkeun Chung ${ }^{1,2} \bowtie$ \\ 'Department of Psychiatry, Chonbuk National University Medical School, Jeonju, Republic of Korea \\ ${ }^{2}$ Research Institute of Clinical Medicine of Chonbuk National University-Biomedical Research Institute of Chonbuk National University Hospital, \\ Jeonju, Republic of Korea
}

Little is known about the risk factors for the fear of falling in elderly Korean individuals. Thus, the present study aimed to investigate the risk factors for fear of falling in a representative elderly population of over 10,000 individuals aged 65 years and older. A multivariate multinomial analysis revealed that the risk factors associated with a severe fear of falling were being female [odds ratio (OR)=4.396], older age ( $\mathrm{OR}=5.550$ for those aged $\geq 85$ years), lower level of education $(\mathrm{OR}=0.719$ for those with $\geq 13$ years of schooling), chronic illness $(\mathrm{OR}=2.788$ for those with more than three chronic illnesses), poor subjective health $(\mathrm{OR}=6.268)$, functional impairments $(\mathrm{OR}=2.340)$, a history of falling $(\mathrm{OR}=7.062)$, and depression $(\mathrm{OR}=1.774)$. The ORs for each of these risk factors were particularly high in participants with a severe fear of falling. Particularly, a history of falling and/or poor subjective health status had strong independent associations with the fear of falling. The present findings may help health care professionals identify individuals that would benefit from interventions aimed at reducing the fear of falling.

Psychiatry Investig 2017;14(6):894-899

Key Words Fear of falling, Risk factor, Depression, Subjective health status.

\section{INTRODUCTION}

Falls are a major threat to the well-being of older adults. Every year, one out of three individuals older than 65 years experiences a fall, ${ }^{1,2}$ which can result in a variety of physical injuries including hip fractures, head traumas, and even an increased risk of early death. Approximately $32 \%$ of falls in older individuals result in severe injuries, which interfere with mobility and independence, or even fall-related death. ${ }^{3}$ The death rate associated with falls among the elderly has sharply increased over the past decade, ${ }^{4}$ during which time more than 19,700 deaths have been caused by unintentional injuries related to a fall. ${ }^{5}$

Because falls and fall-related injuries are not uncommon,

Received: May 23, 2016 Revised: August 1, 2016

Accepted: August 15, 2016 Available online: May 17, 2017

$\triangle$ Correspondence: Sangkeun Chung, MD, PhD

Department of Psychiatry, Chonbuk National University Medical School, 20 Geonji-ro, Deokjin-gu, Jeonju 54907, Republic of Korea

Tel: +82-63-250-1398, Fax: +82-63-275-3157, E-mail: skchung@jbnu.ac.kr

(a) This is an Open Access article distributed under the terms of the Creative Commons Attribution Non-Commercial License (http://creativecommons.org/licenses/by$\mathrm{nc} / 4.0)$ which permits unrestricted non-commercial use, distribution, and reproduction in any medium, provided the original work is properly cited. many elderly individuals worry about falling in later-life. This is an appropriate concern for frail individuals as it may result in the adoption of self-protective measures but it may also result in adverse consequences, such as restricted social participation, functional decline, a decreased quality of life, and, paradoxically, an increased risk of falling. ${ }^{6}$ The fear of falling is thought to be a significant health problem, equal to that of actual falls, ${ }^{7}$ which could increase health care utilization and costs. Fortunately, falls and the fear of falling are public health problems that are largely preventable. Most previous studies that investigated the fear of falling focused on sociodemographic and/or health-related variables, with few reporting on the extensive range of other types of risk factors associated with the fear of falling, including psychological variables such as depression and subjective health status. Thus, not only is there a scarcity of information on various aspects of falls and the fear of falling in Korea, but many studies have also failed to report the type of data necessary to design effective prevention programs for the Korean population. To the best of our knowledge, the present study is the first to investigate the risk factors associated with the fear of falling using a representative sample of over 10,000 elderly subjects in Korea. 


\section{METHODS}

The present study analyzed data from the 2011 Survey of Living Conditions and Welfare Needs of Korean Older Persons (Korea Institute for Health and Social Affairs), ${ }^{8}$ which has been conducted every 3 years since 2008 using representative samples of non-institutionalized elderly people in Korea that were recruited based on a stratified, two-stage cluster sampling design. This survey collected information via face-toface interviews and all participants provided written informed consent; 11,542 elderly individuals older than 60 years completed the survey (response rate $=76.2 \%$ ) but the present analysis was limited to participants older than 65 years of age and ultimately included 10,674 elderly participants. This study was approved by the Research Ethics Committee of Chonbuk National University Hospital.

Fear of falling was assessed by asking the question "Are you afraid of falling?"; the response options of "very much", "somewhat", and "not at all" were recoded as severe, mild, and no fear of falling, respectively. Participants provided sociodemographic information regarding their age, gender, living situation (alone or not), and educational and economic status, as well as information about health-related variables such as chronic illnesses, functional impairments, and history of falls. The number of chronic illnesses was assessed by the question "Do you currently have a chronic illness for more than 3 months, which was diagnosed by a physician?" The chronic illnesses included hypertension, stroke, hyperlipidemia, and ischemic heart disease. Functional impairments were defined as requiring help with personal care on at least one item of the Korean Instrumental Activities of Daily Living (K-IADL) questionnaire. ${ }^{9}$ History of falls was assessed by the question "Have you experienced any falls during last year?"; the participants responded either "yes" or "no."

The psychological variables assessed in the present study included depression and subjective health status. Subjective health status was evaluated by the question "How would you rate your health in general?"; the choices for the subjective health status were classified as very good, good, fair, poor, and very poor. For analysis, subjective health status classified subsequently as "good," "fair," or "poor," which good included very good and good, fair included fair, and poor included poor and very poor. Depression was assessed by the Korean version of the short Geriatric Depression Scale (SGDS). ${ }^{10,11}$ This is a 15-item, self-administered questionnaire on which scores range from $0-15$; a score of 8 or higher is considered to indicate depression.

\section{Statistical analyses}

Univariate analyses (chi-squared tests) were performed to identify associations between fear of falling and the sociodemographic, health-related, and psychological variables. Independent variables that had significant group differences in the univariate analyses were included in a multivariate multinomial logistic regression analysis, which was performed to calculate adjusted odds ratios (OR) for mild and severe fear of falling.

\section{RESULTS}

The univariate analyses revealed the independent variables that were associated with both mild and severe fear of falling (Table 1). Participants with mild and severe fear of falling were more likely to be female, have an older age, live alone, be less educated, have a low economic status, have a chronic illness, have a poor subjective health status, be functionally impaired, have a history of falling, and/or have depression. Of the 10,674 elderly participants assessed in the present study, $21.2 \%$ had experienced a fall during the last 12 months, $32.4 \%$ had a severe fear of falling, and $43.3 \%$ had a mild fear of falling.

The patterns of associations among the fear of falling and its risk factors were similar between those with a mild versus severe fear of falling, but were more evident in participants with a severe fear of falling. The multivariate multinomial regression analysis revealed that a severe fear of falling was independently associated with female gender ( $\mathrm{OR}=4.396)$, older age $(\mathrm{OR}=1.552,2.023,4.243$, and 5.550 for participants aged $70-74,75-79,80-84$, and $\geq 85$ years, respectively), lower level of education ( $\mathrm{OR}=0.804$ and 0.719 for $7-12$ and $\geq 13$ years of schooling, respectively), higher number of chronic illnesses (OR=1.440, 2.396, and 2.788 for one, two, or more than three chronic illnesses, respectively), poor subjective health $(\mathrm{OR}=$ 2.380 and 6.268 for fair and poor health, respectively), and having functional impairment ( $\mathrm{OR}=2.340$ ), a history of falling $(\mathrm{OR}=7.062)$, and depression (OR=1.774), even after controlling for all confounding variables (Table 2). When compared to the ORs for a mild fear of falling, the ORs for a severe fear of falling increased by more than twofold, from 2.316 to 6.268 , for those with a poor subjective health status, and from 2.572 to 7.062 for those with a history of falls.

\section{DISCUSSION}

The present study demonstrated that female gender, older age, less education, chronic illness, poor subjective health status, functional impairments, a history of falls, and depression were risk factors for both mild and severe fear of falling on a multivariate multinomial regression analysis. These associations were more evident in elderly participants with a severe fear of falling than in those with a mild fear of falling. Addition- 
Table 1. Sociodemographic, health-related and psychological characteristics of subjects

\begin{tabular}{|c|c|c|c|c|}
\hline & \multicolumn{3}{|c|}{ Fear of falling } & \multirow{2}{*}{$\mathrm{p}$-value } \\
\hline & No & Mild & Severe & \\
\hline Gender & & & & 0.000 \\
\hline Male & $1,809(70.7)$ & $1,821(39.9)$ & $910(26.7)$ & \\
\hline Female & $748(29.3)$ & $2,741(60.1)$ & $2,498(73.3)$ & \\
\hline Age & & & & 0.000 \\
\hline $65-69 \mathrm{yrs}$ & $1,112(43.5)$ & $1,337(29.3)$ & $694(20.4)$ & \\
\hline $70-74$ yrs & $796(31.1)$ & $1,468(32.2)$ & $962(28.2)$ & \\
\hline $75-79$ yrs & $443(17.3)$ & $1,068(23.4)$ & $873(25.6)$ & \\
\hline $80-84$ yrs & $148(5.8)$ & $451(9.9)$ & $561(16.5)$ & \\
\hline $85+y r s$ & $58(2.3)$ & $237(5.2)$ & $318(9.3)$ & \\
\hline Living alone & & & & 0.000 \\
\hline No & $2,297(89.8)$ & $3,644(79.9)$ & $2,500(73.4)$ & \\
\hline Yes & $260(10.2)$ & $918(20.1)$ & $908(26.6)$ & \\
\hline Educational status & & & & 0.000 \\
\hline No education & $409(16.0)$ & $1,473(32.3)$ & $1,441(42.3)$ & \\
\hline 6 yrs or less & $821(32.1)$ & $1,683(36.9)$ & $1,233(36.2)$ & \\
\hline $7-12$ yrs & $986(38.5)$ & $1,138(24.9)$ & $611(17.9)$ & \\
\hline 13 yrs or more & $342(13.4)$ & $268(5.9)$ & $123(3.6)$ & \\
\hline Economic status & & & & 0.000 \\
\hline 1st quintile & $289(11.3)$ & $923(20.2)$ & $899(26.4)$ & \\
\hline 2nd quintile & $438(17.1)$ & $959(21.0)$ & $718(21.1)$ & \\
\hline 3rd quintile & $547(21.4)$ & $917(20.1)$ & $632(18.5)$ & \\
\hline 4th quintile & $579(22.7)$ & $917(20.1)$ & $616(18.1)$ & \\
\hline 5th quintile & $703(27.5)$ & $846(18.5)$ & $544(16.0)$ & \\
\hline Chronic illness & & & & 0.000 \\
\hline 0 & $575(22.5)$ & $447(9.8)$ & $116(3.4)$ & \\
\hline 1 & $753(29.4)$ & $860(18.8)$ & $408(12.0)$ & \\
\hline 2 & $625(24.4)$ & $1,114(24.4)$ & $812(23.8)$ & \\
\hline More than 3 & $604(23.6)$ & $2,142(46.9)$ & $2,072(60.8)$ & \\
\hline Subjective health status & & & & 0.000 \\
\hline Good & $1,573(61.5)$ & $1,541(33.8)$ & $481(14.1)$ & \\
\hline Fair & $515(20.1)$ & $1,116(24.5)$ & $631(18.5)$ & \\
\hline Poor & $470(18.4)$ & $1,902(41.7)$ & $2,297(67.4)$ & \\
\hline Functional impairment & & & & 0.000 \\
\hline No & $2,467(96.6)$ & $4,113(90.2)$ & $2,591(76.1)$ & \\
\hline Yes & $88(3.4)$ & 447 (9.8) & $814(23.9)$ & \\
\hline History of fall & & & & 0.000 \\
\hline No & $2,408(94.2)$ & 3,807 (83.5) & $2,100(61.6)$ & \\
\hline Yes & $149(5.8)$ & $755(16.5)$ & $1,308(38.4)$ & \\
\hline Depression & & & & 0.000 \\
\hline No & $2,188(85.7)$ & $3,268(71.7)$ & $1,871(54.9)$ & \\
\hline Yes & $365(14.3)$ & $1,289(28.3)$ & $1,534(45.1)$ & \\
\hline
\end{tabular}

All values are unweighted N (\%) to give descriptive statistics on the characteristics of the study sample rather than nationally generalizable estimates 
Table 2. Multinomial logistic regression analysis of variables affecting fear of falling

\begin{tabular}{|c|c|c|c|c|c|c|}
\hline & \multicolumn{3}{|c|}{ Mild } & \multicolumn{3}{|c|}{ Severe } \\
\hline & OR & $95 \% \mathrm{CI}$ & $\mathrm{p}$-value & OR & $95 \% \mathrm{CI}$ & p-value \\
\hline \multicolumn{7}{|l|}{ Gender } \\
\hline Male & 1.000 & Reference & & 1.000 & Reference & \\
\hline Female & 2.767 & $2.447-3.128$ & 0.000 & 4.396 & $3.794-5.093$ & 0.000 \\
\hline \multicolumn{7}{|l|}{ Age } \\
\hline $65-69$ yrs & 1.000 & Reference & & 1.000 & Reference & \\
\hline $70-74$ yrs & 1.350 & $1.186-1.538$ & 0.000 & 1.552 & $1.321-1.823$ & 0.000 \\
\hline $75-79$ yrs & 1.588 & $1.363-1.849$ & 0.000 & 2.023 & $1.687-2.425$ & 0.000 \\
\hline $80-84$ yrs & 2.101 & $1.683-2.623$ & 0.000 & 4.243 & $3.319-5.425$ & 0.000 \\
\hline $85+y r s$ & 2.648 & $1.912-3.668$ & 0.000 & 5.550 & $3.917-7.863$ & 0.000 \\
\hline \multicolumn{7}{|l|}{ Living alone } \\
\hline No & 1.000 & Reference & & 1.000 & Reference & \\
\hline Yes & 1.051 & $0.872-1.266$ & 0.603 & 1.177 & $0.957-1.448$ & 0.122 \\
\hline \multicolumn{7}{|l|}{ Educational status } \\
\hline No education & 1.000 & Reference & & 1.000 & Reference & \\
\hline 6 yrs or less & 0.968 & $0.829-1.129$ & 0.675 & 1.043 & $0.879-1.239$ & 0.628 \\
\hline $7-12$ yrs & 0.822 & $0.696-0.971$ & 0.021 & 0.804 & $0.662-0.976$ & 0.025 \\
\hline 13 yrs or more & 0.673 & $0.538-0.843$ & 0.001 & 0.719 & $0.538-0.961$ & 0.026 \\
\hline \multicolumn{7}{|l|}{ Economic status } \\
\hline 1st quintile & 1.000 & Reference & & 1.000 & Reference & \\
\hline 2nd quintile & 0.991 & $0.812-1.209$ & 0.926 & 1.011 & $0.808-1.264$ & 0.925 \\
\hline 3rd quintile & 0.938 & $0.766-1.149$ & 0.539 & 1.003 & $0.796-1.264$ & 0.980 \\
\hline 4th quintile & 0.993 & $0.809-1.220$ & 0.949 & 1.074 & $0.847-1.361$ & 0.556 \\
\hline 5th quintile & 0.806 & $0.653-0.994$ & 0.044 & 0.870 & $0.681-1.110$ & 0.262 \\
\hline \multicolumn{7}{|l|}{ Chronic illness } \\
\hline 0 & 1.000 & Reference & & 1.000 & Reference & \\
\hline 1 & 1.110 & $0.936-1.315$ & 0.230 & 1.440 & $1.104-1.878$ & 0.000 \\
\hline 2 & 1.428 & $1.201-1.697$ & 0.000 & 2.396 & $1.849-3.103$ & 0.000 \\
\hline More than 3 & 1.837 & $1.537-2.196$ & 0.000 & 2.788 & $2.150-3.616$ & 0.007 \\
\hline \multicolumn{7}{|c|}{ Subjective health status } \\
\hline Good & 1.000 & Reference & & 1.000 & Reference & \\
\hline Fair & 1.570 & $1.368-1.802$ & 0.000 & 2.380 & $1.994-2.840$ & 0.000 \\
\hline Poor & 2.316 & $1.996-2.687$ & 0.000 & 6.268 & $5.251-7.483$ & 0.000 \\
\hline \multicolumn{7}{|c|}{ Functional impairment } \\
\hline No & 1.000 & Reference & & 1.000 & Reference & \\
\hline Yes & 1.358 & $1.053-1.750$ & 0.018 & 2.340 & $1.809-3.027$ & 0.000 \\
\hline \multicolumn{7}{|l|}{ History of fall } \\
\hline No & 1.000 & Reference & & 1.000 & Reference & \\
\hline Yes & 2.572 & $2.117-3.125$ & 0.000 & 7.062 & $5.779-8.630$ & 0.000 \\
\hline \multicolumn{7}{|l|}{ Depression } \\
\hline No & 1.000 & Reference & & 1.000 & Reference & \\
\hline Yes & 1.325 & $1.146-1.533$ & 0.000 & 1.774 & $1.515-2.078$ & 0.000 \\
\hline
\end{tabular}

All logistic regressions are weighted to reflect sampling design 
ally, the importance of these findings was underscored by the fact that psychological factors such as depression and subjective health status had significant associations with fear of falling.

Although it is well-known that elderly individuals have a greater fear of falling if they have a history of falls, a chronic illness, or functional impairments, the present study found that poor subjective health status had the second-highest OR after a history of falls. It is interesting that the elderly participants who had a severe fear of falling had an OR of 6.268 for poor subjective health status, compared to elderly participants with good subjective health, and that elderly participants with depression had a greater fear of falling than those without depression. The present results, showing independent associations between poor subjective health status, depression and a fear of falling, support the findings of previous studies. ${ }^{12,13}$ When elderly individuals evaluate their health as poor, they often lose confidence and tend to become more housebound. Similarly, elderly individuals with depression avoid activities and social interactions and tend to have a more negative view of themselves, which would in turn negatively affect their subjective health status. The fear of falling negatively affects the lives of elderly individuals in various ways. For example, approximately $40 \%$ of elderly individuals avoid activities due to a fear of falling. ${ }^{6,14}$ However, activity restriction in and of itself could be a risk factor for additional falls because it can lead to muscle weakness, poor balance, more frailty, and even social isolation. ${ }^{15}$ Therefore, because psychological variables such as subjective health status and depression are important modifiable risk factors, these variables should be taken into consideration when aiming to prevent and reduce the fear of falling.

Of the sociodemographic variables assessed in the present study, older age and female gender were the only significant risk factors associated with the fear of falling that were also identified in previous studies. ${ }^{6,14}$ The present study also demonstrated that high level of education level had a positive association with the fear of falling, whereas living alone and economic status were not significantly related to fear of falling. Living alone and economic status showed non-significant result in some previous studies. ${ }^{6,7}$ Other than age and gender, many sociodemographic variables have yet to be comprehensively studied and require further investigation.

The present study had several limitations that should be noted. First, a cross-sectional design was used; thus, causal relationships cannot be inferred. Future longitudinal studies are necessary to better understand the risk factors associated with fear of falling. Second, information about the fear of falling and its risk factors was gathered from retrospective self-reports, which may have been influenced by recall bias. However, the study also had several strengths: it focused on diverse risk factors of both mild and severe fear of falling, including psychological variables, and utilized a large sample representative of the elderly population in Korea.

In conclusion, the evidence for older age, female gender, poor subjective health status, functional impairments, a history of falls, and depression as risk factors for fear of falling appears strong, while living alone, educational status, and economic status should be interpreted cautiously. The present findings may offer health care providers valuable insights into the relationships between fear of falling and its major risk factors, including depression, subjective health status, age, and history of falls.

\section{Acknowledgments}

This paper was supported by Fund of Biomedical Research Institute, Chonbuk National University Hospital.

\section{REFERENCES}

1. Hausdorff JM, Rios DA, Edelber HK. Gait variability and fall risk in community-living older adults: a 1-year prospective study. Arch Phys Med Rehabil 2001;82:1050-1056.

2. Hornbrook MC, Stevens VJ, Wingfield DJ, Hollis JF, Greenlick MR, Ory MG. Preventing falls among community-dwelling older persons: results from a randomized trial. Gerontologist 1994:34:16-23.

3. Sterling DA, O'Connor JA, Bonadies J. Geriatric falls: injury severity is high and disproportionate to mechanism. J Trauma 2001;50:116-119.

4. Centers for Disease Control and Prevention (CDC). Fatalities and injuries from falls among older adults--United States, 1993-2003 and 2001-2005. MMWR: Morb Mortal Wkly Rep 2006;55:1221-1224.

5. Centers for Disease Control and Prevention, National Center for Injury Prevention and Control. Web-based Injury Statistics Query and Reporting System (WISQARS) [online]. Available at: https://webappa. cdc.gov/sasweb/ncipc/mortrate.html. Accessed November 30, 2010.

6. Zijlstra GA, van Haastregt JC, van Eijk JTM, van Rossum E, Stalenhoef PA, Kempen GI. Prevalence and correlates of fear of falling, and associated avoidance of activity in the general population of communityliving older people. Age Ageing 2007;36:304-309.

7. Cumming RG, Salkeld G, Thomas M, Szonyi G. Prospective study of the impact of fear of falling on activities of daily living, SF-36 scores, and nursing home admission. J Gerontol A Biol Sci Med Sci 2000;55: M299-M305.

8. Jung KH, Lee YK, Park BM, Lee SJ, Lee YH. Analysis of the Survey of Living Conditions and Welfare Needs of Korean Older Persons. Seoul: Korea Institute for Health and Social Affairs; 2012.

9. Won CW, Rho YG, Sun WD, Lee YS. The validity and reliability of Korean Instrumental Activities of Daily Living (K-IADL) Scale. J Korean Geriatr Soc 2002;6:273-280.

10. Sheikh JI, Yessavage JA. Geriatric Depression Scale (GDS): Recent Evidence and Development of a Shorter Version. In: Brink TL, Editor. Clinical Gerontology: A Guide to Assessment and Intervention. New York, NY; Hallworth, 1986, p.165-174.

11. Bae JN, Cho MJ. Development of the Korean version of the Geriatric Depression Scale and its short form among elderly psychiatric patients. J Psychosom Res 2004;57:297-305.

12. Kempen GI, Haastregt JC, McKee KJ, Delbaere K, Zijlstra GR. Sociodemographic, health-related and psychosocial correlates of fear of falling and avoidance of activity in community-living older persons who avoid activity due to fear of falling. BMC Public Health 2009;9:170.

13. van Haastregt JC, Zijlstra GR, van Rossum E, van Eijk JT, Kempen GI. 
Feelings of anxiety and symptoms of depression in community-living older persons who avoid activity for fear of falling. Am J Geriatr Psychiatry 2008;16:186-193.

14. Howland J, Lachman ME, Peterson EW, Cote J, Kasten L, Jette A. Co- variates of fear of falling and associated activity curtailment. Gerontologist 1998;38:549-555.

15. Gagnon N, Flint A. Fear of falling in the elderly. Geriatr Aging 2003;6: 15-17. 